\title{
Mechanical thrombectomy of COVID-19 DVT with congenital heart disease leading to phlegmasia cerulea dolens: a case report
}

\author{
Neema Jamshidi ${ }^{*}$ (D), Weiyi Tan², Dingle Foote ${ }^{1}$, Leigh Reardon², Gentian Lluri², Jamil Aboulhosn²,
} John Moriarty ${ }^{1,2}$ and Jeannette Lin ${ }^{2^{*}}$

\begin{abstract}
Background: COVID-19 and Fontan physiology have each been associated with an elevated risk of venous thromboembolism (VTE), however little is known about the risks and potential consequences of having both.

Case presentation: A 51 year old male with tricuspid atresia status post Fontan and extracardiac Glenn shunt, atrial flutter, and sinus sick syndrome presented with phlegmasia cerulea dolens (PCD) of the left lower extremity in spite of supratherapeutic INR in the context of symptomatic COVID-10 pneumonia. He was treated with single session, catheter directed mechanical thrombectomy that was well-tolerated.

Conclusions: This report of acute PCD despite therapeutic anticoagulation with a Vitamin K antagonist, managed with emergent mechanical thrombectomy, calls to attention the importance of altered flow dynamics in COVID positive patients with Fontan circulation that may compound these independent risk factors for developing deep venous thrombosis with the potential for even higher morbidity.
\end{abstract}

Keywords: Femoral and iliac vein thrombosis, Venous thromboembolism, Mechanical thrombectomy, ClotTriever, Fontan, Case report

\section{Background}

COVID-associated coagulopathy has recently been described [1] and COVID VTE is recognized to be significantly elevated in critically ill patients [2-4]. Patients with altered Fontan physiology have independently elevated risks of developing VTE due to decreased pulmonary arterial pressures. Meta-analyses are now reporting risk factors for DVT development including hypoalbuminemia and higher Sequential Organ Failure Assessment (SOFA) scores [5]. However the risk for VTE in

*Correspondence: njamshidi@mednet.ucla.edu; jeannettelin@mednet.ucla. edu

1 Department of Radiological Sciences, UCLA, 757 Westwood Ave, Ste 2125, Los Angeles, CA 90095, USA

${ }^{2}$ Department of Internal Medicine/Division of Cardiology, UCLA, 757 Westwood Ave, Ste 2125, Los Angeles, CA 90095, USA the context of altered cardiopulmonary circulation due to congential heart disease (CHD) remains largely unknown.

\section{Case presentation}

A 51-year-old male with tricuspid atresia, status post atriopulmonary Fontan at 6 years of age with subsequent urgent surgical conversion to an extracardiac Fontan (Fig. 1) in the setting of a right atrial thrombus at 30 years of age. The patient initially presented to an outpatient clinic with cough and diarrhea. He was diagnosed with SARS-CoV-2 infection via nasopharyngeal swab. Six days later, he presented to a rural emergency room with progressive exertional dyspnea, and was found to be hypoxic and hypotensive. He was diagnosed with COVID-19 pneumonia (Fig. 2), the patient was placed 


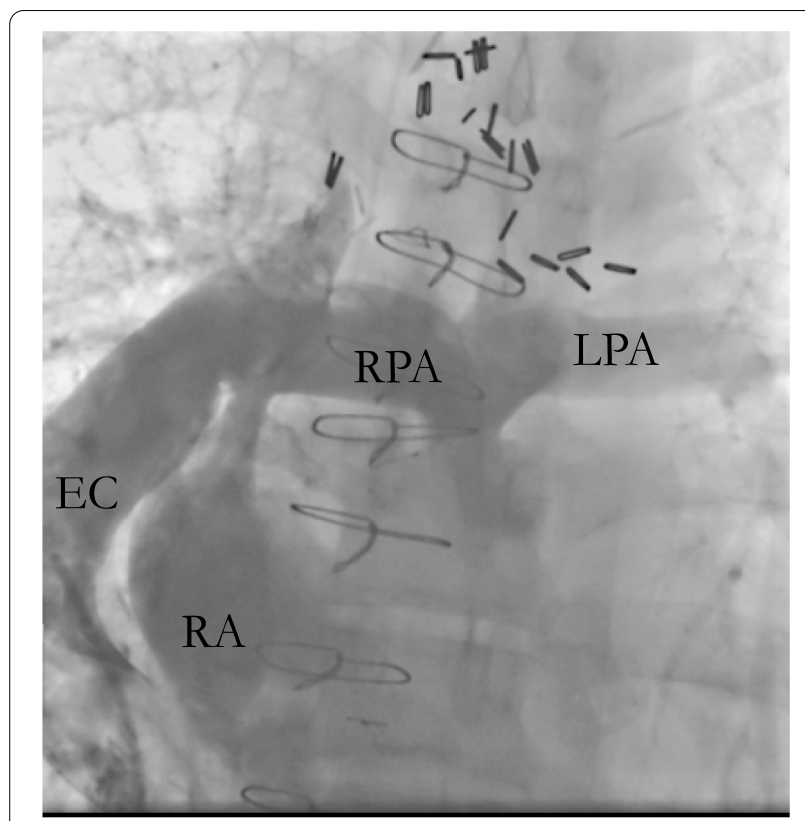

Fig. 1 Central venogram highlighting Fontan circulation with extracardiac shunt. EC extracardiac Fontan conduit, $R A$ right atrium, $R P A$ right pulmonary artery, $L P A$ left pulmonary artery on bilevel positive airway pressure (BiPAP) and vasopressor support. He received a course of remdesivir and was continued on tadalafil. Warfarin was held due to a supratherapeutic international normalized ratio (INR) greater than 14. His respiratory status improved and he was weaned to a non-rebreather mask. He developed bilateral leg pain during the hospitalization, and lower extremity venous ultrasound detected bilateral deep vein thromboses. Given these findings, he was urgently transferred to our institution on hospital day (HD) 7 for higher level of care (Table 1).

Upon transfer, his INR was down-trending, but remained supratherapeutic at 6.6 , and computed tomography venogram (CTV) demonstrated bilateral deep venous thrombosis from the iliac to calf veins, excluding the inferior vena cava (IVC). There was no evidence of pulmonary embolus. Physical exam was notable left lower leg findings pitting edema, purple discoloration (Figs. 3, 4), decreased sensation, and mobility. The laboratory workup was notable in particular for the supratherapeutic INR that was reduced to 1.6 by the second day of hospitalization at our institution, following treatment with Vitamin K. DIC panel and prothrombotic workup, including $\beta-2$ glycoprotein and cardiolipin antibodies, were negative (Table 2 ).
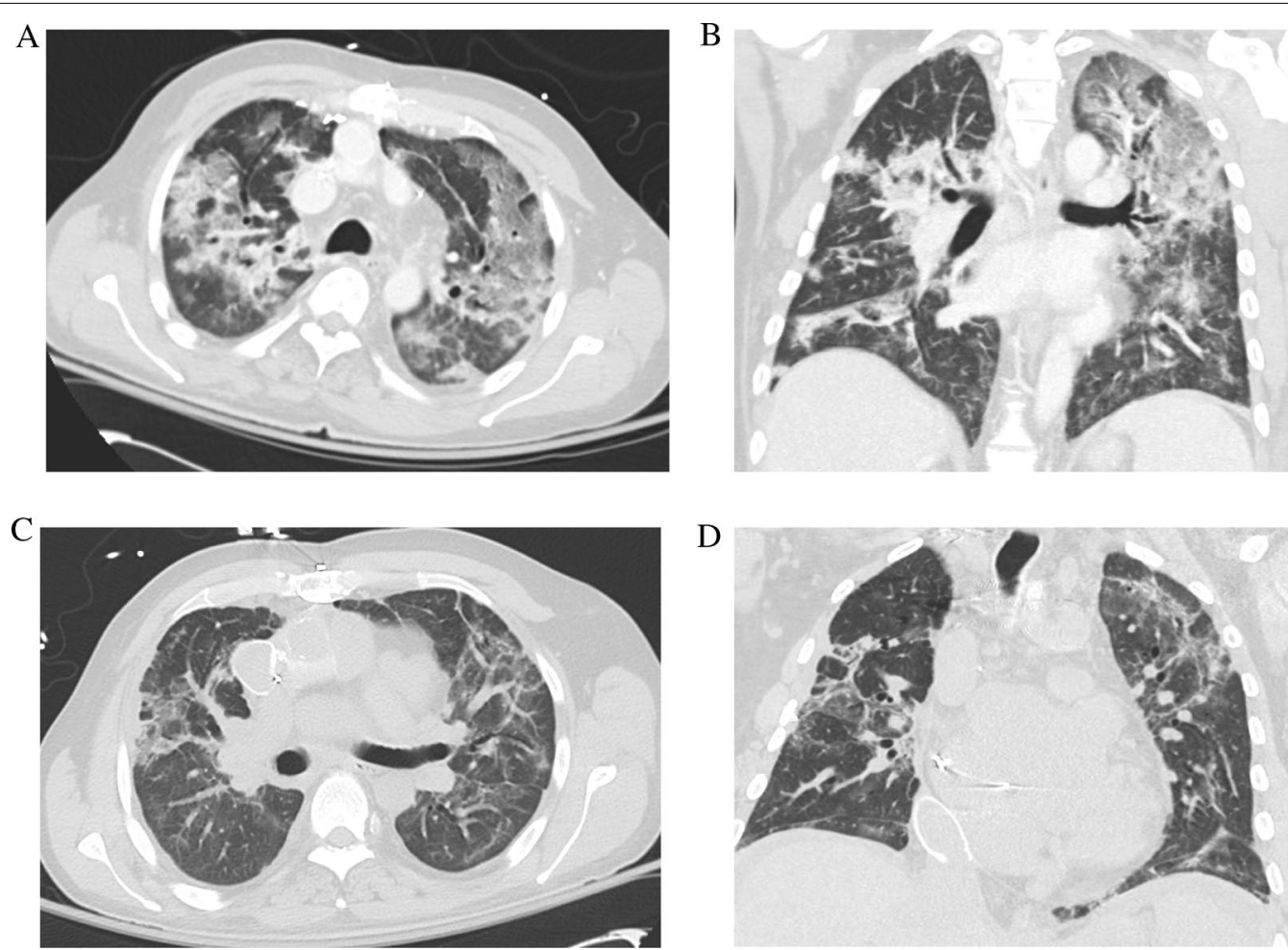

Fig. 2 Multifocal pneumonia consistent with clinical presentation and laboratory studies for COVID-19 (A, B). Subsequent axial and coronal slices showing resolution of COVID-19 pneumonia with pulmonary fibrosis (C, D) 
Table 1 Timeline for the key events from initial presentation, hospitalization, and transfer to our institution

\begin{tabular}{|c|c|}
\hline Day 1 & $\begin{array}{l}\text { Patient presentation to outpatient clinic with upper respiratory and gastrointestinal symptoms, diagnosed with SARS- } \\
\text { CoV-2 infection via nasopharyngeal swab }\end{array}$ \\
\hline Day 7 (OSH HD 1) & $\begin{array}{l}\text { Presentation to community hospital with hypoxia and hypotension with COVID-19 pneumonia requiring BiPAP and vasopressor } \\
\text { support }\end{array}$ \\
\hline Day 12 (HD 1) & $\begin{array}{l}\text { Patient transfered to our healthcare facility for higher level of care with subsequent mechanical thrombectomy of bilateral lower } \\
\text { extremities }\end{array}$ \\
\hline Day 13 & Bilateral iliac filters retrieved with patent IVC and iliac veins \\
\hline Day 41 & Left below the knee amputation was performed \\
\hline Day 50 & Patient discharged to rehabilitation facility \\
\hline
\end{tabular}

OSHD Outside Hospital Day, HD Hospital Day (our institution)

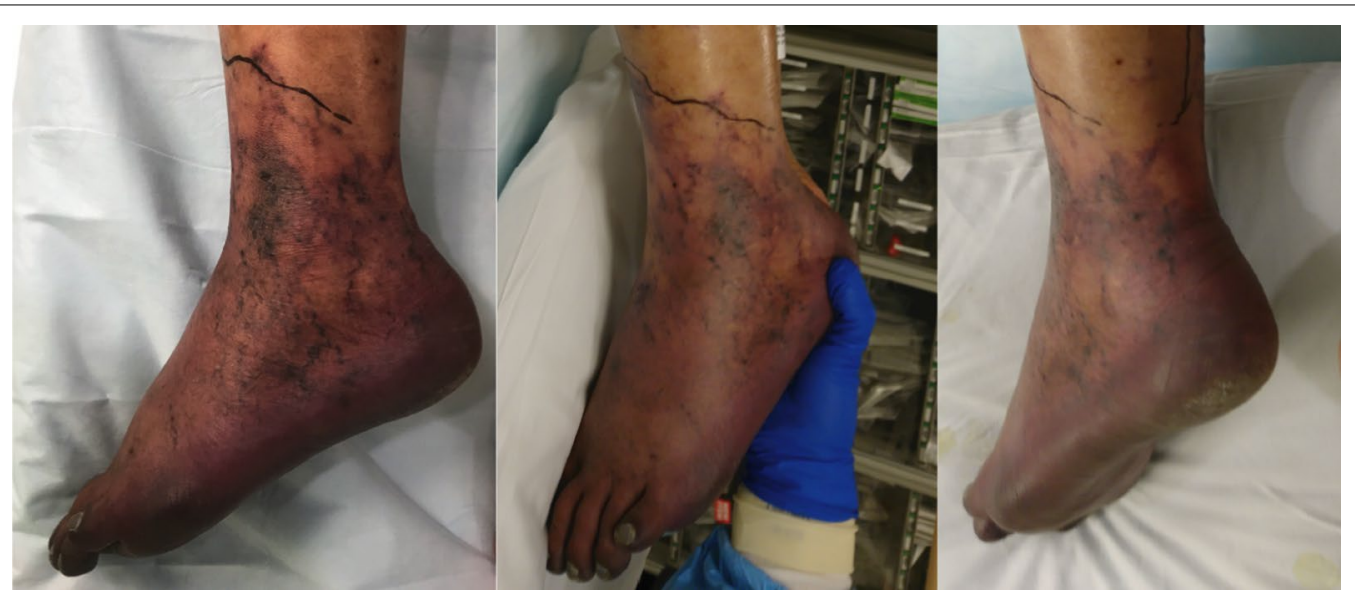

Fig. 3 Painful, violaceous foot, concerning for venous outflow obstruction resulting in PCD

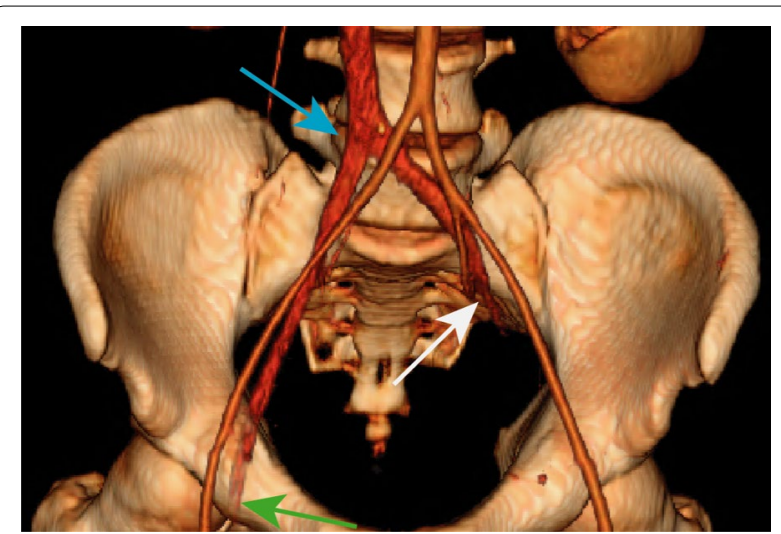

Fig. 4 Color-rendered 3D reconstruction of the pelvis outlining the patent arterial vasculature (aorta and bilateral iliac arteries) and IVC with bilateral venous thromboses. The white, green, and blue arrows indicate the abrupt completely occlusive thrombus of the proximal left common iliac vein, the occlusive thrombus of the right common femoral vein, and the iliac confluence into the IVC, respectively
While the differential diagnosis of limb ischemia in the setting of COVID-19 infection includes arterial thrombosis, the demonstration of venous outflow obstruction (Fig. 4), violaceous discoloration of the lower extremity, pronounced edema, and pain confirmed the diagnosis of phlegmasia cerulea dolens (PCD). A heparin drip was initiated with vitamin K reversal of warfarin. Since his partial thromboplastin time (PTT) values were abnormal (Table 2), anti-Xa levels were used to titrate the heparin infusion. He also received convalescent plasma [6]. Arterial Doppler was notable for biphasic waveforms with excessive diastolic reversed flow concerning for developing compartment syndrome, without evidence of arterial thrombosis.

Following multidisciplinary evaluation, the decision was made undergo an emergent transvenous thrombectomy to salvage the left leg. Given the inflammatory nature of the clot and development of PCD in spite 
Table 2 Relevant laboratory values on admission (Day 12/HD 1)

\begin{tabular}{|c|c|c|}
\hline & Value & Normal range \\
\hline White blood cell count & 8.17 & $4.16-9.95 \times 10 \mathrm{E} 3 / \mathrm{uL}$ \\
\hline Red blood cell count & 3.22 & $4.41-5.95 \times 10 \mathrm{E} 6 / \mathrm{uL}$ \\
\hline Hemoglobin & 11.6 & $13.5-17.1 \mathrm{~g} / \mathrm{dL}$ \\
\hline Hematocrit & 35.7 & $38.5-52.0 \%$ \\
\hline Mean corpuscular volume & 91.5 & 79.3-98.6 fl \\
\hline Mean corpuscular hemoglobin & 30.7 & $26.4-33.4 \mathrm{pg}$ \\
\hline MCH concentration & 33.3 & $31.5-35.5 \mathrm{~g} / \mathrm{dL}$ \\
\hline Platelet count & 137 & $143-398 \times 10 \mathrm{E} 3 / \mathrm{uL}$ \\
\hline Ferritin & 522 & $8-350 \mathrm{ng} / \mathrm{mL}$ \\
\hline Prothrombin time & 16.7 & $11.5-14.4 \mathrm{~s}$ \\
\hline INR & 6.6 & $<1.1$ \\
\hline APTT & 78.5 & $24.4-36.2 \mathrm{~s}$ \\
\hline D-dimer & 5,164 & $\leq 499 \mathrm{ng} / \mathrm{mL} \mathrm{FEU}$ \\
\hline Factor V (5) activity & 113 & $>50 \%$ act \\
\hline Fibrinogen & 526 & $235-490 \mathrm{mg} / \mathrm{dL}$ \\
\hline Sodium & 138 & $135-146 \mathrm{mmol} / \mathrm{L}$ \\
\hline Potassium & 4.1 & $3.6-5.3 \mathrm{mmol} / \mathrm{L}$ \\
\hline Chloride & 101 & $96-106 \mathrm{mmol} / \mathrm{L}$ \\
\hline Total CO2 & 25 & 20-30 mmol/L \\
\hline Anion gap & 12 & 8-19 mmol/L \\
\hline Glucose & 115 & $65-99 \mathrm{mg} / \mathrm{dL}$ \\
\hline GFR estimate for non-African American & $>89$ & $\begin{array}{l}>89 \mathrm{~mL} / \\
\mathrm{min} / 1.73 \mathrm{~m} 2\end{array}$ \\
\hline Creatinine & 0.96 & $0.60-1.30 \mathrm{mg} / \mathrm{dL}$ \\
\hline Urea Nitrogen & 24 & $7-22 \mathrm{mg} / \mathrm{dL}$ \\
\hline Calcium & 7.6 & $8.6-10.4 \mathrm{mg} / \mathrm{dL}$ \\
\hline Magnesium & 1.9 & $1.4-1.9 \mathrm{mEq} / \mathrm{L}$ \\
\hline Phosphorus & 2.7 & $2.3-4.4 \mathrm{mg} / \mathrm{dL}$ \\
\hline Phosphorus & 2.7 & $2.3-4.4 \mathrm{mg} / \mathrm{dL}$ \\
\hline Lactate dehydrogenase & 336 & $125-256 \mathrm{U} / \mathrm{L}$ \\
\hline Total protein & 5.8 & $6.1-8.2 \mathrm{~g} / \mathrm{dL}$ \\
\hline Albumin & 2.2 & $3.9-5.0 \mathrm{~g} / \mathrm{dL}$ \\
\hline Bilirubin, total & 3.2 & $0.1-1.2 \mathrm{mg} / \mathrm{dL}$ \\
\hline Bilirubin, conjugated & 2.6 & $\leq 0.3 \mathrm{mg} / \mathrm{dL}$ \\
\hline Alkaline phosphatase & 63 & $37-113 \mathrm{U} / \mathrm{L}$ \\
\hline Aspartate aminotransferase & 32 & $13-47 \mathrm{U} / \mathrm{L}$ \\
\hline Alanine aminotransferase & 11 & 8-64 U/L \\
\hline
\end{tabular}

of supratherapeutic INR, mechanical thrombectomy was felt to be the most appropriate course of action [7] as opposed to 'lyse and wait' strategies that could prolong vascular compromise and also subject the patient to increased adverse bleeding events and the potential development of compartment syndrome.

Bilateral popliteal vein access was obtained for catheter directed mechanical thrombectomy using the ClotTriever $^{\circledR}$ system (Inari Medical). Popliteal and Fontan pressures were 19 and $17 \mathrm{mmHg}$, respectively; pulmonary angiography did not demonstrate any emboli. Five thrombectomy passes of the left lower extremity from the popliteal vein to the IVC and four passes of the right leg successfully restored flow from the bilateral popliteal veins to the IVC (Fig. 5) and yielded thrombus that was positive for SARS-CoV-2 by polymerase chain reaction (PCR). In order to protect the cardiopulmonary circulation peri-procedurally during anticoagulation optimization, bilateral retrievable iliac vein filters (Optease) were placed. An IVC filter was not placed due to the large size of the cava. The iliac filters were retrieved on HD 12 via femoral approach (the right internal jugular vein was chronically occluded) following venograms confirming patent femoral and iliac veins. A left lower extremity cellulitis developed and empirically managed with antibiotics. The patient unfortunately did not have reversal of the ischemic changes post-procedure, requiring below-theknee amputation (BKA) for dry gangrene of the left foot.

He experienced epistaxis while on heparin, that was treated with nasal packing. There was evidence of postpneumonia fibrosis [8] (Fig. 2C and 2D); the associated increase in pulmonary vascular resistance is often not well tolerated in Fontan patients [9]. His tadalafil was increased to $40 \mathrm{mg}$ daily from $20 \mathrm{mg}$ daily to improve hemodynamics. His oxygen saturation was eventually maintained on room air and he never required mechanical ventilation. The BKA was well tolerated and on HD 50 he was discharged to an acute rehabilitation unit on warfarin.

\section{Discussion and conclusions}

Patients with a Fontan circulation are at higher risk for thrombus formation [10]. The systemic venous return drains directly into the pulmonary arteries, and the lack of a subpulmonary ventricle results in a low-flow state through the pulmonary arterial circuit. Pulmonary venous return thus depends on negative inspiratory intrathoracic pressure, low pulmonary vascular resistance, and diastolic function of the systemic ventricle. Increases in pulmonary vascular resistance due to pulmonary infections, positive-pressure ventilation, and/or atrial arrhythmias can all decrease pulmonary blood flow $[10,11]$. Patients with COVID-19 infection are at higher risk for thrombosis due to multiple theorized factors, including an increased inflammatory state and endothelial cell dysfunction secondary to viral invasion [12, 13]. PCD in patients with COVID-19 has been reported [1], but thus far only in patients predisposed to thrombosis. In our case, our patient's cardiac anatomy and physiology placed him in a higher risk category, and despite treatment with a vitamin $\mathrm{K}$ antagonist with supratherapeutic levels, he developed extensive bilateral venous thromboses. Interestingly his pulmonary circulation was 

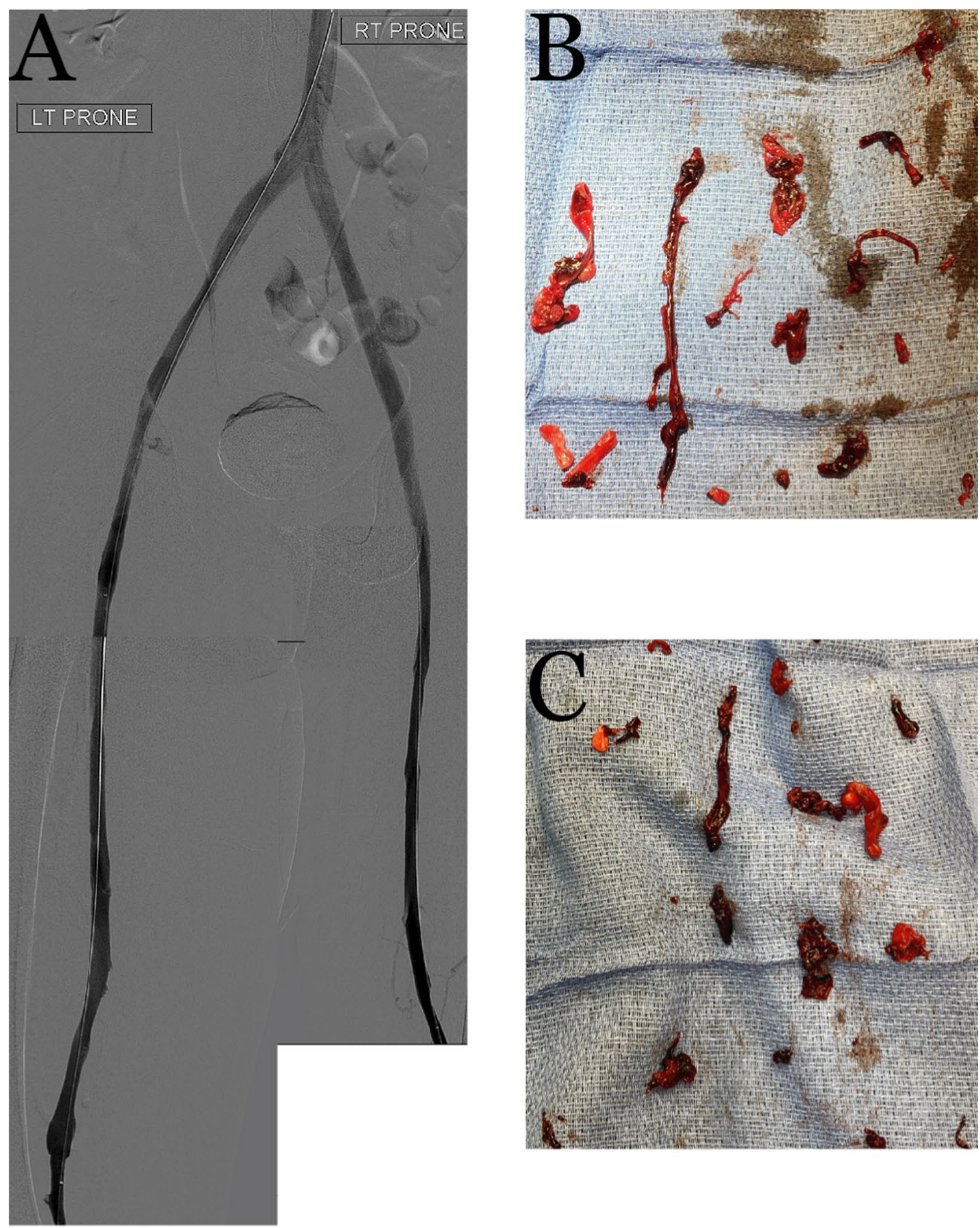

Fig. 5 Post-thrombectomy lower extremity venograms (A) with corresponding photographs of the pathology-confirmed COVID-19-positive extracted thrombus from the left (B) and right (C) lower extremities

intact and he did not develop any evidence of pulmonary emboli on CTA or pulmonary angiography.

PCD requires aggressive therapy for limb salvage [14], but resource limitations in heavily impacted hospitals during the COVID pandemic may result in delays in diagnosis and treatment. Nevertheless, the treatment this patient received likely prevented further leg ischemia and limited his amputation to below-the-knee instead of above-the-knee, which is associated with improved functionality and long-term outcomes [15].

Presently, the most effective anticoagulation strategy for patients with COVID-19 related thrombosis is unclear. Our patient developed no further thrombosis while on heparin, though notably this change was made after the COVID pneumonia was already improving. 
Patients with comorbidities that place them in higherrisk categories for various disease states, such as Fontan circulation, are potentially at higher risk of complications from COVID-19. PCD is a rare but devastating complication, and must be recognized early and treated aggressively; mechanical thrombectomy may be indicated to expedite restoration of venous outflow, particularly when anticoagulation may be contraindicated. Pulmonary fibrosis secondary to COVID-19 may lead to increased pulmonary vascular resistance, which may further complicate the long-term course of Fontan patients in particular. Despite the presence of acute lung injury and extensive deep venous thromboses, our patient did not require mechanical ventilation or develop decompensated heart failure, reflecting a reassuring degree of resilience of this patient's Fontan circulation in the face of COVID-19 infection.

\section{Abbreviations}

BKA: Below-the-knee amputation; PCD: Phlegmasia cerulea dolens; PTT: Partial thromboplastin time; CTV: Computed tomography venogram; IVC: Inferior vena cava; HD: Hospital day; BiPAP: Bilevel positive airway pressure; VTE: Venous thromboembolism; DIC: Disseminated intravascular coagulation; PCR: Polymerase chain reaction.

\section{Acknowledgements}

Not applicable.

\section{Authors' contributions}

$\mathrm{NJ}, \mathrm{DF}, \mathrm{JM}$ were involved with acquisition of and interpretation of patient data. $L R, G L, J A$, and $J L$ were involved with acquisition of data. NJ, DF, and WW drafted the manuscript with substantial revisions by JL. All authors contributed to the editing of the manuscript and agreed on the final content. All authors read and approved the final manuscript.

\section{Funding}

No funding sources.

\section{Availability of data and materials}

The datasets used and/or analysed during the current study available from the corresponding authors on reasonable request.

\section{Declarations}

\section{Ethics approval and consent to participate}

The Institutional Review Board waived full board review for the presentation of this anonymized case report. The authors attest they are in compliance with human studies committees and animal welfare regulations of the authors' institutions and Food and Drug Administration guidelines.

\section{Consent for publication}

The authors confirm that written consent for submission and publication of this case report including images and associated text has been obtained from the patient in line with COPE guidelines.

\section{Competing interests}

JM is a consultant for Argon Medical, Angiodynamics Inc, Boston Scientific Inc, Inari Medical, Penumbra Inc, BD Bard, Thrombolex Inc, and Pavmed Inc. The other authors have no conflicts to disclose.

Received: 23 January 2021 Accepted: 24 November 2021

Published online: 09 December 2021

\section{References}

1. Morales MH, Leigh CL, Simon EL. COVID-19 infection with extensive thrombosis: a case of phlegmasia cerulea dolens. Am J Emerg Med. 2020;38(9):1978 e1-e3.

2. Middeldorp S, Coppens M, van Haaps TF, et al. Incidence of venous thromboembolism in hospitalized patients with COVID-19. J Thromb Haemost. 2020;18:1995-2002.

3. Visveswaran GK, Morparia K, Narang S et al. Severe acute respiratory syndrome coronavirus 2 infection and thrombosis: phlegmasia cerulea dolens presenting with venous gangrene in a child. J Pediatr. 2020;226:281-4 e1.

4. Bamgboje A, Hong J, Mushiyev S, Pekler G. A 61-year-old man with SARSCoV-2 infection and venous thrombosis presenting with painful swelling and gangrene of the lower limb consistent with phlegmasia cerulea dolens. Am J Case Rep. 2020;21:e928342.

5. Chen S, Zhang D, Zheng T, Yu Y, Jiang J. DVT incidence and risk factors in critically ill patients with COVID-19. J Thromb Thrombolysis. 2021:51(1):33-9.

6. Li L, Zhang W, Hu Y, et al. Effect of convalescent plasma therapy on time to clinical improvement in patients with severe and life-threatening COVID-19: a randomized clinical trial. JAMA. 2020;324(5):460-70.

7. Oguzkurt L, Ozkan U, Demirturk OS, Gur S. Endovascular treatment of phlegmasia cerulea dolens with impending venous gangrene: manual aspiration thrombectomy as the first-line thrombus removal method. Cardiovasc Intervent Radiol. 2011;34:1214-21.

8. Spagnolo P, Balestro E, Aliberti S, et al. Pulmonary fibrosis secondary to COVID-19: a call to arms? Lancet Respir Med. 2020;8(8):750-2.

9. Gewillig M, Brown SC. The Fontan circulation after 45 years: update in physiology. Heart. 2016;102:1081-6.

10. Marrone C, Galasso G, Piccolo R, et al. Antiplatelet versus anticoagulation therapy after extracardiac conduit Fontan: a systematic review and metaanalysis. Pediatr Cardiol. 2011;32:32-9.

11. Fredenburg TB, Johnson TR, Cohen MD. The Fontan procedure: anatomy, complications, and manifestations of failure. Radiographics. 2011:31:453-63.

12. Connors JM, Levy JH. COVID-19 and its implications for thrombosis and anticoagulation. Blood. 2020;135:2033-40.

13. Mondal S, Quintili AL, Karamchandani K, Bose S. Thromboembolic disease in COVID-19 patients: a brief narrative review. J Intensive Care. 2020;8:70.

14. Mumoli N, Invernizzi C, Luschi R, Carmignani G, Camaiti A, Cei M. Phlegmasia cerulea dolens. Circulation. 2012;125:1056-7.

15. Hagberg E, Berlin OK, Renstrom P. Function after through-knee compared with below-knee and above-knee amputation. Prosthet Orthot Int. 1992;16:168-73.

\section{Publisher's Note}

Springer Nature remains neutral with regard to jurisdictional claims in published maps and institutional affiliations.

Ready to submit your research? Choose BMC and benefit from

- fast, convenient online submission

- thorough peer review by experienced researchers in your field

- rapid publication on acceptance

- support for research data, including large and complex data types

- gold Open Access which fosters wider collaboration and increased citations

- maximum visibility for your research: over $100 \mathrm{M}$ website views per year

At BMC, research is always in progress.

Learn more biomedcentral.com/submissions 